\title{
Review on the Ten Educational Elements in "My Own Swordsman"
}

\author{
Fubin Han \\ Office of Educational Affairs \\ Hengshui University \\ Hengshui, China \\ e-mail: hanfubin1975@163.com
}

\author{
Jianmei Dong \\ Department of Politics and Law \\ Hengshui University \\ Hengshui, China \\ e-mail: dongjianmei1974@163.com
}

\begin{abstract}
The TV play "My Own Swordsman" is a comedy popular with the audience because of its humorous plot. This play contains many educational topics such as the Chinese pedagogical notion---"to teach by the students' aptitude", psychological education, personality education, entrance education, environmental protection education and so on, which is of important educational value to elementary and secondary education.
\end{abstract}

Keywords-TV play; My Own Swordsman; educational elements; personality education; financial education

\section{INTRODUCTION}

The TV play "My Own Swordsman", a very popular comedy with humorous language, special style and various topics in China, was released 10 years ago. With the development of fast-food culture, most people are easily drawn by the players' humorous act, language and the vivid plots of the drama and it is very hard for them to tap and refine the educational elements which are of individual and social value. After all, the name of the TV play "My Own Swordsman" does't show any concern with education because it is not a comedy with pure educational topics but one with a main line of feelings between men and women concerning various topics. Generally speaking, the TV play "My Own Swordsman" contains a variety of educational elements and gives us profound warnings in retrospect.

This paper contends that this TV play mainly contains ten educational elements: the Chinese pedagogical notion---"to teach by the students' aptitude" put forward by the famous educator Confucius, personality education which is a new modern educational notion, psychological education, financial education which is a new form of family education in China, animal protection education, environmental protection education which is a global issue, anti-superstitious education, anti-pyramid schemes education, literacy education and entrance education.

\section{EUCATIONAL ELEMENTS}

Although the TV play "My Own Swordsman" is a comedy based on the feeling line of the characters, there are many chapters telling the audience all kinds of educational stories with retrospection.

\section{A. Personality Education}

Personality education is to cultivate and develop the students' positive personality traits, such as interests, independence and sense of social responsibility, to tap every student's potentials and to promote the development of their advantages[1]. The TV play "My Own Swordsman" describes and shows every character's distinctive temperament. For example, there are characters like wise and clever Zhantang Bai, easy-going Furong Guo, learned and overconfident Qinghou Lu, kind-hearted and loyal Dazui Li. Here come two kinds of educational notion in this context. One is the conservative and traditional education ideology represented by Xiangyu Tong, the leading role in "My Own Swordsman". Another one is the open and democratic educational ideology represented by other characters. These two kinds of education have a great influence on Xiaobei Mo who is the niece of Xiangyu Tong. In the whole TV play, although Xiaobei Mo is easier to be influenced by the open and democratic educational ideology of other characters, the influence from her sister-in-law's conservative and traditional education ideology is more significant than others. All the influences make Xiaobei Mo keep calm when facing all kinds of major issues of principle. Luckily Mister Zhu, the teacher of Xiaobei Mo, is not pedantic. He didn't scold Xiaobei Mo when she ruined the extinct book of Song Dynasty. On the contrary, Mr. Zhu believed Xiaobei Mo was a ballsy girl who dare to break the mold. This also creates a relaxed environment for her to learn and grow. So at last Xiaobei Mo develops an active, brave and independent character which builds a good basis for her to act as the head of Mount Heng Sect in the future.

This makes us reflect on our education at present. Some scholars believe that personality education is the focus, starting point and end-result of quality-oriented education which is the main theme of Chinese education. In fact, the examples of over-suppressed personality, creativity and thought are easy to be seen in our daily life[2]. For example, we take college entrance examination as the baton of elementary education. This leads to the fact that thousands of primary and secondary schools cannot implement quality-oriented education effectively. The only choice for them is to sacrifice the students' personality education in order to get good exam results. Thus we must urgently reform the current education system from the aspects of educational idea, policy, content, approach and so on and effectively implement quality-oriented 
education to cultivate talents with characteristics, pioneering spirit and strong practical abilities.

\section{B. Entrance Education}

Here the entrance education is not school education but part of family education. It means the things parents do to prepare their children to go to school like doing some shopping for them or escorting them to school. In the 3rd Chapter of the TV play "My Own Swordsman", all the guys become the Staff of Xiaobei Mo after she builds eight Schools aiming to reflect on the entrance education. Over time, Xiaobei Mo comes to the age of school. Xiangyu Tong, the innkeeper in the play, decides to let her register White Horse Academy, the most famous school in the local colleges nearby. At last Xiaobei Mo gets the entrance qualification successfully because Furong Guo replaced her exam. Xiangyu Tong is very happy with the news because she can't read or write. Then she spends a whole night to make a pair of shoes, clothes and a schoolbag by herself for Xiaobei Mo and prepares handsome gifts for the teachers hoping that they can take good care of Xiaobei Mo in school. Besides, Xiangyu Tong makes Furong Guo the servant girl of Xiaobei Mo, Qinghou Lü the boy servant in her studies, Dazui $\mathrm{Li}$ the bearer and Zhantang Bai the bodyguard to escort Xiaobei Mo to school.

In China, with the implement of "One-child "policy since 1970s, there are more and more one-childs. Many parents spoil their child. Especially in September every year, during the enrollment time of Colleges and Universities, parents escort their child to colleges, help the child go through all the procedures, do shopping, make beds, wash clothes and cook for him or her. Parents who involve too much in their child's educational affairs are called inspiringly "helicopter parents" in western countries [3]. Although parents do help the children temporally, in fact, it will do harm to develop their ability of taking care of themselves. So we suggest that parent do not over-interfere their children's affairs but lend hands when their children are in need indeed.

\section{Teaching by the Students' Aptitude}

The great educational notion "to teach by the students' aptitude" was firstly put forward by the famous Chinese educator "Confucius". Zhuxi, a famous ideologist in Song Dynasty, summarized it as "Confucius teaching by the students' aptitude".

This notion is expressed in chapter 9 of the TV play "My Own Swordsman". The 2nd son of a ministry councilor, the 3rd son of a shopkeeper and the daughter of a widow in the small town fight for the prizes in the organ, five-in-a-row and handwriting competitions respectively. Xiangyu Tong forces Xiaobei Mo to learn Chinese chess from Qinghou Lü, Xiao, a vertical bamboo flute, and handwriting from Furong Guo in order become confident in public. Later she asks Mr Dou to teach Xiaobei drawing. In fact, Xiaobei isn't interested in all those things. Finally,Mr Dou finds out that Xiaobei is interested in making clay figures. He explains to Xiangyu Tong patiently and intently that parents first need to consider why children learn things before what they learn. We should support them if the children learn out of interest and we must stop if we make them do something out of our vanity. As we know, all work and no play makes Jack a dull boy. We should create a relaxed environment for children to develop their imagination and creativity. Every child will create miracles as long as they get interested and they will return you surprises if you offer them the opportunity. What Mr Dou says makes Xiangyu Tong give up her original idea at last.

Although the education notion "to teach by students' aptitude" has been popular in China for thousands of years, saying is always easier than doing. In schools today, "to teach by the students' aptitude" is still difficult. Some scholars think that "to teach by students' aptitude" is not the requirement for all teachers but the final goal of education [4].Indeed, every teacher and parent should learn the great educational notion by heart and carry it out in their school and family education. We believe that there are not bad students but poor teachers in the world.

\section{Psycological Education}

Owing to the quickening pace of life, people pay more and more attention to psychological education. In the chapter 29 and 44 of the TV play "My Own Swordsman", Qinghou Lü skilled Wulong Sun and Wuming Ji, two scoundrels. Qinghou Lü is not only a scholar sympathizing the poor but also a psychologist with a wide range of knowledge. In the comedy, there are two evildoers and one is Wulong Gongsun and another is Wumin Ji. They both have redoubtable Kungfu and have killed many martial arts masters. The government provides rewards for their capture. When they come into Xiangyu's inn for accommodation, Qinghou uses his abundant knowledge on criminal psychology to analyze their psychology. He bravely attacks them by means of psychological language so that the two greatest burglars get scared. Gongsun Wulong is imprisoned and Wuming Ji commits suicide because of nervous breakdown.

As we all know, many college students are suffering from all kinds of psychological problems with more and more serious situation of unemployment. They do not know what career path to choose, what field of study to pursue or even how to get along well with others. Some researchers have pointed out that dependency, inferiority, conformity, and cognitive bias are the psychological traits typical of Chinese college students [4]. According to a survey, 36 percent of college students feel diffident and anxious; 21 percent don't know what to think of anyone else and lack communication skills (particularly in interviews); and 23 percent simply don't know how to communicate with others[5]. So in our opinion, the government should build up an open, equal, and fair employment environment for graduates by expanding the job markets and implementing employment laws and regulations so as to ensure fair competition and alleviate employment pressure. Teachers should shift from lecture-based pedagogy to interactive pedagogy; they should explain complex topics clearly, in layman's or "plain" language; and they should teach with enthusiasm and humor. Students should master the following interpersonal skills: making a good first impression, initiating communication with others, being helpful, appreciating others, no criticizing or complaining about others in public, and never telling lies. 


\section{E. Financial Education}

By comparison, Western countries have the tradition of implementing financial education in schools and families. In the chapter 38 of the TV play "My Own Swordsman", Xiaobei Mo is punished by copying "The Three-Character Classic" for three times by Xiangyu Tong because she forgets to tell her sister-in-law to skate on a river on the vacation. Xiaobei is mad at the punishment. So Xiangyu Tong bets that Xiaobei may exempt from punishment if she can make $150 \mathrm{~g}$ silver as the innkeeper in 3 days. Thereafter, Xiaobei and her classmate Xiaodong Qiu makes an operating plan to attract guests by staging performances, but it doesn't work. On the 3rd day they stew a kind of porridge called "tiandiwuji porridge". But unfortunately a beggar named Xiaomi almost dies after he drinks their porridge. Therefore, Xiaobei's plans come to nothing.

From this chapter we know although Xiaobei and her classmate make no money by operating Xiangyu's inn, they still have imagination and operating ablility. And it also tells us that financial education is an important part of our career. Some scholars believe that students in primary and secondary schools are in lack of financial awareness and ability totally. They cannot even manage their money and stuff until college. That is mainly due to the fact that their parents conduct no financial education when their children were young [6]. It is helpful for children to implement financial education by teaching them to value labor, money and so on. So parents should help their children make plans to implement financial education to develop their financial awareness and ability.

\section{F. Anti-pyramid Schemes Education}

As we all know, there has been two kinds of sales modes in the world: traditional way of selling and direct selling. In China, Direct Selling Regulations and Prohibition of Pyramid Selling Regulations were issued in 2005 to regulate and guide direct selling. Still, others point out there are signs of growing problems for the direct-selling industry. Pyramid Selling can cheat money in many forms.

The chapter 41 of the TV play "My Own Swordsman" shows us a vivid pyramid selling story. Many years later Dazui Li luckily meet his sweetheart---Lan Hui. But now Lan Hui has strayed into a pyramid selling called "kitchen knife school". She asks Dazui Li to buy three kitchen knives at $150 \mathrm{~g}$ silver and explains the promotion system of kitchen knife school. Dazui $\mathrm{Li}$ is in love with her and doesn't know the cheat. As a result, he cannot get the love from Lan Hui and loses his money.

Today, the illegal pyramid selling organizations still work in secret ways. It may not hurt a lot of people and their friends and relatives greatly but can seriously disrupt the market order. Some national websites ban illegal pyramid selling activities on the web. So in school education we should bring the illegal pyramid selling into the content of safety education curriculum and help students know its nature and its harm to society. To some degree, the TV play "My Own Swordsman" is a helpful comedy for people.

\section{G. Animal Protection Education}

It is imperative to promote publicity and educational work concerning the protection of precious and rare wild animals so as to form powerful public force to support this task. The Chapter 58 of the TV play "My Own Swordsman" presents a new actor----Canhua Nangong, the little school-sister of Xiangyu Tong. Nangong is a vegetarian and stops Dazui Li from killing cocks. She tells him that everything has life. Cocks can feel pain because they have blood and meat. Besides, she persuades others to bring their leather goods and bury them by telling vivid moving stories. And then, Nangong forbids people eating any animal. People are unsatisfied with her but don't talk back for the inn's sake.

Although What Nangong has done in the inn aggravates someone, her idea of protecting animals is valuable. We all know the number of many species is becoming smaller and smaller and some species are on the edge of extinction due to environment pollution and hunting and killing. Some experts believe that the main reason lies in the unsound animal protection law [6]. Besides, we have no animal protection awareness and don't cherish the life of creatures since teenage. So the law of animal protection needs to be propagandized in primary and secondary schools and enhance people's awareness of taking care of animals.

\section{H. Environment and Health Education}

Similarly, the environment and Health education is being paid more and more attention by people. The author of the TV play "My Own Swordsman" seizes on this and arranges a series of health education in the comedy.

Encouraged by Nangong's example, the fellows in the inn begin to eat no meat and use no leather. They begin to clean their inn and street actively. Xiaobei Mo helps them hand out leaflets of environment protection. She tells people that our heath will be harmed if the environment is polluted.

In addition, the characters of the TV play "My Own Swordsman" tell us the knowledge about food nutrition in the way of true confession that attracts the audience deeply.

With the development of social economy, the ecological environment of our country is being destroyed such as air, river and soil pollution. At the same time, poor eating habits and lifestyles both have a great influence on people's health. All of this warns us that we must persist in the idea of scientific development and develop a good way of life.

\section{Literacy Education}

The the TV play "My Own Swordsman" is just like a kaleidoscope which can reflect all kinds of social problems.

In chapter 61 of the TV play "My Own Swordsman", the line of literacy education is inserted. Xiangyu Tong reminds people of literacy education when others are doing some cleaning and propagandizing environment protection. She tells Qinghou Lü to take on the heavy responsibility of literacy education. And she hopes that the all the people in the town could recite Chinese three-character Classic, pass the CET, TOEFL and GRE. In a word, people should develop in an all-around way and know what should be done and what should not.

In 2004, A Alleviation Program for Elimination Illiteracy and popularization of compulsory education was implemented 
formally by the State Council of China. It pointed out that we should basically eliminate illiteracy among young and middle-aged adults and popularize the compulsory education in the western area until 2007. At that time, the broadcast of the TV play "My Own Swordsman" expresss a great support for national education situation.

\section{J. Anti-superstitious Education}

The new China was born in a semi-feudal and semi-colonial society in last century, so feudalism and superstition still exist.

In chapter 42 of the TV play "My Own Swordsman", a wizard puts his hands in a boiling oil pan and isn't hurt. Zhantang Bai reveals the fraud of the fortune-teller and wizard.

John $\cdot \mathrm{C} \cdot$ Burnam, a professor in history from Ohio State University, explains to us an interesting and puzzling phenomenon. Science and technology can get an upper hand in attacking superstition and pseudo-science when it is weak, but it has dominated China for so long. After world war II, pseudo-science and superstition are reported constantly in all kinds of media[7]. Beijing Science and Technology daily reported on many feudalist superstitions and pseudo-science such as identifying Chinese characters with ears, extraordinary function of human body and so on, but they are all spread by some leaders and experts. Another newspaper reported that the cars of leaders continuously come to Mount Heng for blessing in every Spring Festival. The first stick of incense could be worth 100 thousand yuan[8]. So we think the broadcast of the TV play "My Own Swordsman" is the best response to fight against superstitious activities.

\section{CONCLUSION}

After the analysis the 10 educational elements in the TV play "My Own Swordsman", we conclude:

- The TV play "My Own Swordsman" is not a comedy but a kaleidoscope. It tells us many kinds of social problems.

- The TV play "My Own Swordsman" can keep pace with times and reflect the important things in different times.

- The TV play "My Own Swordsman" is a modern comedy with special educational values.

Finally, we hope that more and more comedies like "My Own Swordsman" can be released on TV and can also come into thousands of households around the world.

\section{ACKNOWLEDGMENT}

The authors are grateful to Hengshui University Science Funds for financial assistance in support of this study.

\section{REFERENCES}

[1] Xiujing Wang, "A Research on the Absence and Construction of Personality Education for Junior High School in China,"May 2013, unpublished.

[2] Qian Lin,Personality Education: It's Hhard to Love You,Jiangxi Educational Eesearch,vol.40,p.62,2005.
[3] PingCai,the"Helicopter Parents"in American Universities,http://www.

[4] lajiaocit.com/publishihtml/15/2005-09-16/20050916072516.html.200

[5] 5-09-16/2007-10-12.

[6] Yulin Liu and Qi Yuan, The psychological confusion of college students during job-seeking and countermeasures,Managers' Journal. Vol.7,pp.161-62, 2009.

[7] Aihua Yang, Study of the problem and countermeasures of interpersonal contact for college students, Tangdu Journal. Vol.23,pp,126-28, 2008.

[8] Lei Zhang and Jing Song,on the legality of wild animal protection, Journal of Shanxi Politics and Law Institute for Administratiors, Vol.27,pp.13-14,2014.

[9] Weixing Niu,Our Scientific Culture:Superstitions Defeat Science?SH: East China Normal University Press,2007.

[10] Youren Wen,Leaders and Authority experts shouldn't do Pseudoscience,Beijing Science and Technology News,2007-1-19. 